\section{Outbreak and control of haemorrhagic pneumonia due to Streptococcus equi subspecies zooepidemicus in dogs}

\author{
M. K. KIM, H. JeE, S. W. ShIN, B. C. LeE, \\ B. PAKHRIN, H. S. Yoo, J. H. YooN, \\ D. Y. KIM
}

NECROTISING haemorrhagic pneumonia due to infection with Streptococcus equi subspecies zooepidemicus has been described in dogs (Garnett and others 1982, Chalker and others 2003). The severity of pulmonary disease in a population of kennelled dogs with endemic infectious respiratory diseases has been correlated with the presence of $S$ equi subspecies zooepidemicus. The pathogen has also been isolated from horses, cows, pigs, sheep, goats, guinea pigs, dogs and domestic fowl, and interspecies transmission has been suspected (Biberstein and Hirsh 1999, Quinn and others 2003, Greene 2006)

This short communication describes an outbreak and the immediate control of $S$ equi subspecies zooepidemicusinduced haemorrhagic pneumonia in a research dog colony. Prompt fluid and antibiotic therapies were initiated, and clinical problems were stabilised within two weeks after the initial presentation without further progression.

Twenty-five adult mixed-breed dogs had been kept separated in a metal cage in a research facility at the College of Veterinary Medicine, Seoul National University. Three days before the incident began, four dogs from a private kennel were moved into the colony. Ten dogs, including newly introduced dogs, developed acute signs that included a moist cough, depression, anorexia, fever, dyspnoea and nasal discharge. Seven dogs, including all four newly introduced dogs, died two to 12 hours after first showing clinical signs.

Blood samples taken from three moribund dogs revealed leucopenia ( 1.8 to $3.2 \times 10^{12}$ white blood cells) with monocytosis (68 per cent), a strong indication of acute bacterial infection. There were no apparent abnormalities in the serum chemistry profiles. Radiographic examination revealed that the affected dogs had increased pulmonary opacity to the point where almost the entire lung was affected, except the caudodorsal area. The increase in pulmonary opacity was attributable to bilateral alveolar infiltration, which revealed typical air bronchograms and air alveolograms, particularly in the cranial lobes.

Postmortem examination was performed on the seven dogs soon after death to determine the cause of the outbreak. At postmortem examination the lungs were diffusely haemorrhagic, wet and failed to collapse (Fig 1). A large amount of haemorrhagic frothy fluid was present in the trachea and bronchial airways on cut sections. The nasal cavity and thorax were filled with bloody fluid. No other significant gross abnormalities were found in the thoracic and abdominal cavities. For light microscopic examination, samples from the major parenchymal organs, including lungs, were collected, fixed in 10 per cent phosphate-buffered neutral formalin, routinely processed and stained with haematoxylin and eosin for histopathology. Portions of the lungs were obtained aseptically and used for routine aerobic and anaerobic bacterial cultures. The samples

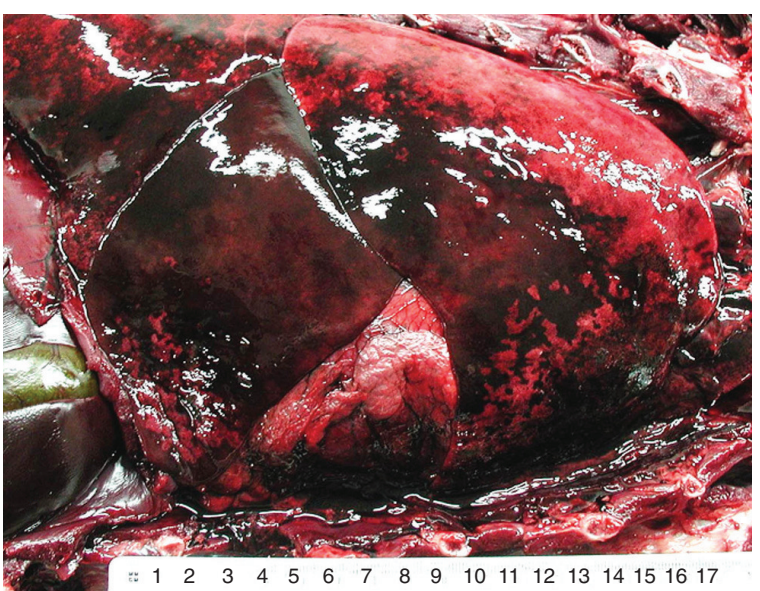

FIG 1: Lung from a dog with a history of epistaxis and respiratory distress. All the lobes are haemorrhagic and moist, with consolidation. Scale $=c \mathrm{~m}$

were plated on to blood agar and incubated for 24 hours at $37^{\circ} \mathrm{C}$; the bacterial colonies were identified using the Vitek system (bioMériex). Further molecular identification was performed by detection of the gene 23S rRNA, sodA (encoding superoxide dismutase A), see $\mathrm{H}$ and seeI (encoding the superantigenic toxins see $\mathrm{H}$ and seeI), using PCR, as previously described by Alber and others (2004) and Kawata and others (2004).

Histopathologically, the pulmonary architecture was obscured by haemorrhage and inflammation. The bronchus, bronchioles and alveolar lumens were diffusely infiltrated with necrotic debris and inflammatory cells, which consisted of predominantly neutrophils and a few lymphocytes, plasma cells and macrophages (Fig 2). Alveolar septa were also hyperaemic. No evidence of septicaemic thrombi was observed in any other organ examined.

Bacteria were isolated in pure culture from the lung and were identified as Streptococcus equi using the Vitek system. The isolate was $23 \mathrm{~S}$ rRNA, sodA-positive, and see $\mathrm{H}$ and seeInegative (Fig 3). The PCR result was consistent with that of $S$ equi subspecies zooepidemicus.

An antimicrobial susceptibility test was performed on the isolate using 17 antimicrobial drugs, by the disc diffusion method. A sensitivity test revealed that the isolate was

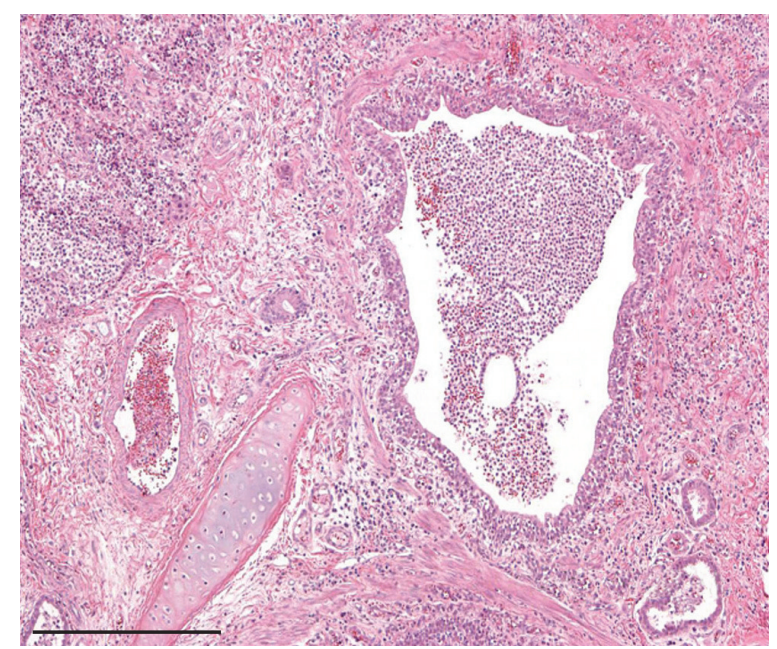

FIG 2: Photomicrograph of the lung of a dog. The alveoli and bronchioles are diffusely filled with erythrocytes, necrotic debris and inflammatory cells. Bar $=100 \mu \mathrm{m}$
Veterinary Record (2007) $161,528-530$

M. K. Kim, DVM, PhD,

B. C. Lee, DVM, PhD,

Departments

of Veterinary

Theriogenology and

Biotechnology,

H. Jee, DVM,

B. Pakhrin, DVM,

D. Y. Kim, DVM, PhD,

Department of Veterinary Pathology,

S. W. Shin, DVM,

H.S. Yoo, DVM, PhD,

Department of Veterinary Infectious Disease,

J. H. Yoon, DVM, PhD, Department of Veterinary Radiology, College of Veterinary Medicine, Seoul National University, 151-742, Seoul, Korea

Correspondence to Dr D. Y. Kim 
FIG 3: Electrophoretic analysis of PCR-amplified products from Streptococcus equi isolates and Streptococcus pyogenes. Lanes 1, 2, 3, 4 PCR-amplified products from the isolates using primers specific for 235 rDNA, sodA, seeH and seel, respectively;

lanes 5, 6, 7, 8 PCR-amplified products from $S$ pyogenes using primers specific for 23S rDNA, sodA, seeH and seel, respectively; Lane M DNA size marker (100 base pair [bp] ladder; Intron). The PCR products of the $S$ equi isolates have sizes of approximately 399 bp (lane 1) and 320 bp (lane 2); the PCR products of $S$ pyogenes have sizes of approximately 500 bp (lane 7) and 520 bp (lane 8). The $S$ equi isolates had negative reactions with oligonucleotide primers for seeH (lane 3) and seel (lane 4); $S$ pyogenes had negative reactions with oligonucleotide primers for 23S rDNA (lane 5) and sodA (lane 6)

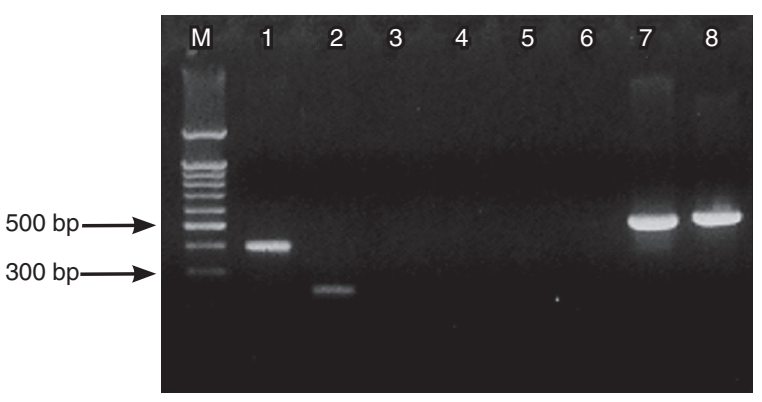

authors' knowledge, this is the first outbreak of haemorrhagic pneumonia due to $S$ equi subspecies zooepidemicus with successful and immediate control by prompt fluid and antibiotic therapy in a research dog colony in Korea.

\section{ACKNOWLEDGEMENTS}

This work was supported by the Brain Korea 21 Program for Veterinary Science and the Korea Research Foundation (KRF2004-005-E00077).

highly sensitive to penicillin (Penicillin; Becton Dickinson) and enrofloxacin (Baytril; Oxoid). An intravenous infusion of lactated Ringer's solution was given to the three moribund dogs at a maintenance rate of $75 \mathrm{ml} / \mathrm{kg} /$ day. A combined preparation of penicillin and streptomycin (consisting of 40,000 iu penicillin and $20 \mathrm{mg} / \mathrm{kg}$ streptomycin) (PPS; Dae Sung Microbiological Labs) was also given intramuscularly every 12 hours. This treatment was effective and resolved the dogs' clinical problems promptly.

$S$ equi is usually divided into two subspecies, subspecies zooepidemicus and subspecies equi. Both are a part of the normal bacterial flora in horses (Ruoff 1992). S equi acts as an opportunistic pathogen that can cause disease in the upper respiratory tract, uterus, umbilicus and in wounds. Subspecies zooepidemicus is associated with several diseases, including lower respiratory tract disorder in horses, pneumonia in ponies and llamas, cervicitis, septicaemia and arthritis in pigs, and mastitis in ruminants (Timoney 1987, Timoney and others 1988, Chanter 1997, Biberstein and Hirsh 1999, Heras and others 2002). Pneumonia and glomerulonephritis due to $S$ equi subspecies zooepidemicus have also been reported in human beings (Barnham and others 1987, Balter and others 2000).

On the basis of the bacterial isolation together with the histopathological findings, $S$ equi subspecies zooepidemicus was identified as the aetiological agent of this outbreak. Possible primary viral infections including canine parainfluenza, canine adenovirus type 1 and canine distemper virus were ruled out using appropriate antigen detection methods and histopathology. While this article was being prepared, another $S$ equi subspecies zooepidemicus epidemic was suspected in the private kennel that had supplied the four dogs involved in the outbreak in the research colony. The authors hypothesise that the outbreak described might have been triggered in the newly acquired dogs by the stress of transportation and joining the colony, possibly associated with an underlying viral infection, since clinical signs were first noticed in these dogs. Tracheal swabs taken from dogs that remained clinically healthy during the outbreak were negative for $S$ equi.

In conclusion, $S$ equi subspecies zooepidemicus should be considered as another definitive causative agent of haemorrhagic pneumonia in dogs, and special caution should be given since interspecies transmission may be possible. To the

\section{References}

ALBER, J., EL-SAYED, A., LAMMLER, C., HASSAN, A. A., WEISS, R. R. \& ZSCHOCK, M. (2004) Multiplex polymerase chain reaction for identification and differentiation of Streptococcus equi subsp zooepidemicus and Streptococcus equi subsp equi. Journal of Veterinary Medicine B. Infectious Diseases and Veterinary Public Health 51, 455-458

BALTER, S., BENIN, A., PINTO, S. W. L., TEIXEIRA, L. M., ALVIM, G. G., LUNA, E., JACKSON, D., LACLAIRE, L., ELLIOT, J., FACKLAM, R. \& SCHUCHAT, A. (2000) Epidemic nephritis in Nova Serrana, Brazil. Lancet 355, 1776-1780

BARNHAM, M., LJUNGGREN, A. \& MCINTYRE, M. (1987) Human infection with Streptococcus zooepidemicus (Lancefield group C); three case reports. Epidemiology and Infection 98, 183-190

BIBERSTEIN, E. L. \& HIRSH, D. C. (1999) Streptococci. In Veterinary Microbiology. 1st edn. Eds D. C. Hirsh, Y. C. Zee. Oxford, Blackwell Science. pp 120-126

CHALKER, V. J., BROOKS, H. W. \& BROWNLIE, J. (2003) The association of Streptococcus equi subsp zooepidemicus with canine infectious respiratory disease. Veterinary Microbiology 95, 149-156

CHANTER, N. (1997) Streptococci and enterococci as animal pathogens. Journal of Applied Microbiology 83 (Suppl 1), 1005-1095

GARNETT, N. L., EYDELLOTH, R. S., SWINDLE, M. M., VONDERFECHT, S. L., STRANDBERG, J. D. \& LUZARRAGA, M. B. (1982) Hemorrhagic streptococcal pneumonia in newly procured research dogs. Journal of the American Veterinary Medical Association 181, 1371-1374

GREENE, C. E. (2006) Streptococcal and other gram-positive bacterial infections. In Infectious Diseases of the Dog and Cat. 3rd edn. Eds C. E. Greene, J. F. Prescott. Philadelphia, Saunders. pp 302-316

HERAS, L. A., VELA, A. I., FERNANDEZ, E., LEGAZ, E., DOMINGUEZ, L. \& FERNANDEZ-GARAYZABAL, J. F. (2002) Unusual outbreak of clinical mastitis in dairy sheep caused by Streptococcus equi subsp zooepidemicus. Journal of Clinical Microbiology 40, 1106-1108

KAWATA, K., ANZAI, T., SENNA, K., KIKUCHI, N., EZAWA, A. \& TAKAHASHI, T. (2004) Simple and rapid PCR method for identification of streptococcal species relevant to animal infectious based on 23S rDNA sequence. FEMS Microbiology Letters 237, 57-64

QUINN, P. J., MARKEY, B. K. \& MAGUIRE, D. (2003) Streptococci. In Concise Review of Veterinary Microbiology. 1st edn. Oxford, Blackwell Publishing. pp 18-19

RUOFF, K. L. (1992) Group C streptococci: a current view. Clinical Infectious Diseases $15,175-176$

TIMONEY, J. F. (1987) The Streptococci. In Pathogenesis of Bacterial Infections in Animals. 2nd edn. Eds C. L. Gyles, C. O. Theon. Ames, Iowa State University Press. pp 12-13

TIMONEY, J. F., GILLESPIE, J. H., SCOTT, F. W. \& BARLOUGH, J. E. (1988) The genus Streptococcus. In Hagan and Bruner's Microbiology and Infectious Diseases of Domestic Animals. 8th edn. Ithaca, London, Comstock Publishing Associates. pp 188-192 